\title{
High concentrations and turnover rates of DMS, DMSP and DMSO in Antarctic sea ice
}

\author{
Elizabeth C. Asher, ${ }^{1}$ John W. H. Dacey, ${ }^{2}$ Matthew M. Mills, ${ }^{3}$ Kevin R. Arrigo, ${ }^{3}$ \\ and Philippe D. Tortell ${ }^{3,4}$ \\ Received 22 September 2011; revised 31 October 2011; accepted 1 November 2011; published 14 December 2011.
}

[1] The vast Antarctic sea-ice zone (SIZ) is a potentially significant source of the climate-active gas dimethylsulfide (DMS), yet few data are available on the concentrations and turnover rates of DMS and the related compounds dimethylsulfoniopropionate (DMSP) and dimethylsulfoxide (DMSO) in sea ice environments. Here we present new measurements characterizing the spatial variability of DMS, DMSP, and DMSO concentrations across the Antarctic SIZ, and results from tracer experiments quantifying the production rates of DMS from various sources. We observed extremely high concentrations $(>200 \mathrm{nM})$ and turnover rates $\left(>100 \mathrm{nM} \mathrm{d}^{-1}\right)$ of DMS in sea-ice brines, indicating intense cycling of $\mathrm{DMS} / \mathrm{P} / \mathrm{O}$. Our results demonstrate a previously unrecognized role for DMSO reduction as a major pathway of DMS production in Antarctic sea ice. Citation: Asher, E. C., J. W. H. Dacey, M. M. Mills, K. R. Arrigo, and P. D. Tortell (2011), High concentrations and turnover rates of DMS, DMSP and DMSO in Antarctic sea ice, Geophys. Res. Lett., 38, L23609, doi:10.1029/2011GL049712.

\section{Introduction}

[2] The biogenic gas dimethylsulfide (DMS) is produced by various biotic and abiotic processes in the surface ocean and ventilated to the overlying atmosphere where it undergoes oxidation to form aerosols that backscatter incoming solar radiation, influence atmospheric acidity and serve as cloud condensation nuclei [Breider et al., 2010; Korhonen et al., 2008; Shaw, 1983]. It has been suggested that oceanic DMS emissions may act as a biological climate feedback mechanism [Charlson et al., 1987] and recent modeling studies have predicted climate-dependent changes in the marine DMS cycle [Bopp et al., 2003; Bopp et al., 2004; Cameron-Smith et al., 2011; Gabric et al., 2001; Gabric et al., 2004; Vallina and Simo, 2007]. The Southern Ocean is the largest natural source of DMS to the atmosphere [Lana et al., 2011], contributing more than $50 \%$ of the total $\mathrm{S}$ aerosols in the Southern Hemisphere [Bates et al., 1992; Chin et al., 2000]. Recent work has also documented high concentrations of DMS and the related compounds

\footnotetext{
${ }^{1}$ Department of Earth and Ocean Sciences, University of British Columbia, Vancouver, British Columbia, Canada.

${ }^{2}$ Biology Department, Woods Hole Oceanographic Institution, Woods Hole, Massachusetts, USA.

${ }^{3}$ Department of Environmental Earth Systems Science, Stanford University, Stanford, California, USA.

${ }^{4}$ Department of Botany, University of British Columbia, Vancouver, British Columbia, Canada.

Copyright 2011 by the American Geophysical Union. 0094-8276/11/2011GL049712
}

dimethylsulfoniopropionate (DMSP) and dimethylsulfoxide (DMSO) in the sea-ice zone (SIZ) adjacent to polynya waters [Brabant et al., 2011; Tison et al., 2010; Trevena and Jones, 2006; Zemmelink et al., 2005, 2008]. At present, the spatial and temporal coverage of sea ice sulfur measurements remains severely limited.

[3] The dominant marine source of DMS is believed to be the enzymatic cleavage of algal-derived DMSP. While some marine algae (including $P$. antarctica) can directly catalyze the breakdown of intracellular DMSP to DMS, field studies indicate that the majority of DMSP cleavage may be derived from bacterial metabolism of the dissolved DMSP pool [Kiene et al., 2000; Simo and Pedros-Alio, 1999]. A number of studies have also demonstrated the potential for biological reduction of DMSO by marine bacteria and phytoplankton as a source of DMS [Fuse et al., 1995; Gonzalez et al., 1999; Spiese et al., 2009; Vila-Costa et al., 2006], though direct measurements of this process in oceanic waters are lacking. Physiochemical conditions in Antarctic sea-ice (near freezing temperatures, high UV, strong salinity and nutrient gradients) may lead to elevated $\mathrm{DMS} / \mathrm{P} / \mathrm{O}$ production by algae, given the hypothesized role of these compounds in cryoprotection, osmo-regulation, and as cellular anti-oxidants [Hatton et al., 2004; Sunda et al., 2002; Stefels et al., 2007]. However, the connections between these physiochemical conditions and high sea ice $\mathrm{DMS} / \mathrm{P} / \mathrm{O}$ concentrations in situ remain obscure.

\section{Methods}

[4] To examine the spatial distribution of DMS, DMSP, and DMSO across the Antarctic SIZ, we sampled 16 sea-ice stations and one open-water station in the Ross Sea polynya on a transit through the Amundsen and Ross Seas on board the Ice Breaker Oden during the middle of the Austral summer (Dec. 2010 - to Jan. 2011; Figure S1). Stations in first-year pack ice, multiyear pack ice, and land-fast ice were sampled to determine DMS, total DMSO (DMSOt; i.e., dissolved and particulate forms), and total and dissolved DMSP $\left(\mathrm{DMSP}_{\mathrm{t}}\right.$ and $\left.\mathrm{DMSP}_{\mathrm{d}}\right)$ in sea-ice brines, ice-covered seawater, surface slush and melt ponds. Samples were collected in Teflon PFA bags and measurements were made using a custom-built gas chromatographic system and capillary inlet quadropole mass spectrometer (see auxiliary material for details). ${ }^{1}$

[5] Isotope tracer studies were conducted at five stations in sack hole brines to measure the production and consumption rates of DMS through various pathways. Our tracer

${ }^{1}$ Auxiliary materials are available in the HTML. doi:10.1029/ 2011 GL049712. 


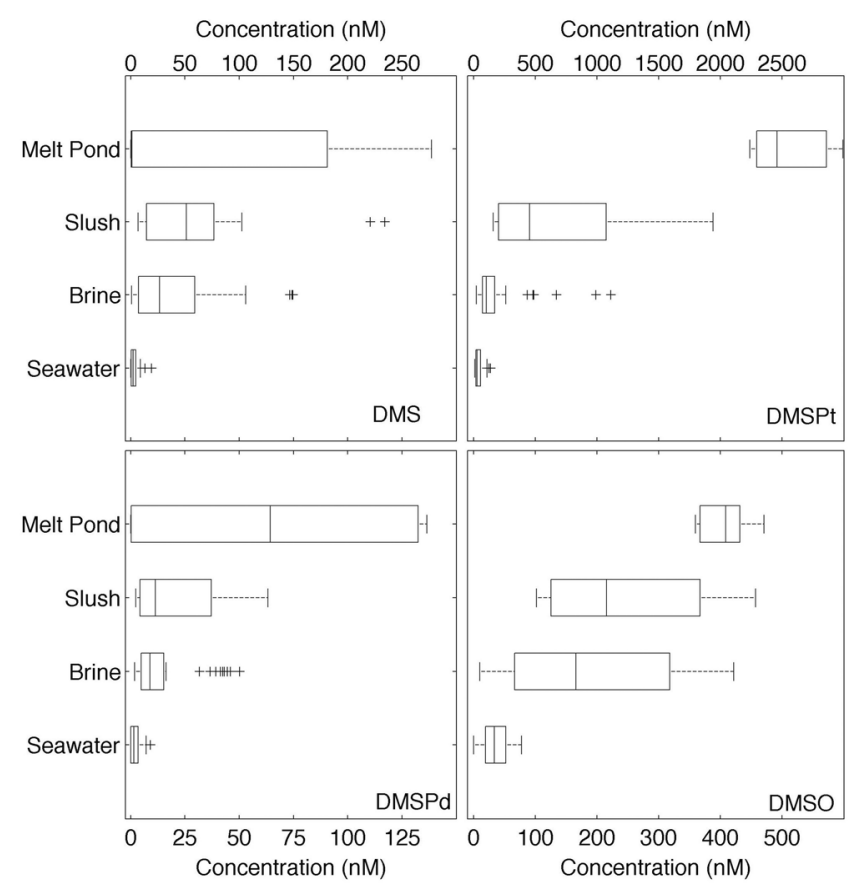

Figure 1. Box plot summarizing the DMS, DMSP $\mathrm{DMSP}_{\mathrm{d}}$, and $\mathrm{DMSO}_{\mathrm{t}}$ concentrations based on sample type across 16 ice and seawater sampling stations. Sample types (shown on the $y$-axis) are in order of relative sample depth. On each box, the central mark represents the data median, while the edges represent the 25th and 75th percentiles $(\mathrm{n} \geq$ 92). The error bars represent the range of data, with '+' signs denoting outliers 1.5 times beyond the inner quartile range (IQR).

approach uses the simultaneous addition of DMS, DMSP and DMSO with different ${ }^{2} \mathrm{H}$ and/or ${ }^{13} \mathrm{C}$ signatures, which can be individually tracked during a short-term incubation experiment (Figure S2). This technique enables the simultaneous quantification of DMS derived from DMSP cleavage and DMSO reduction, gross DMS loss, and the net change in DMS concentrations (i.e. gross production - gross consumption). DMS production from DMSP cleavage was measured as the rate of accumulation of ${ }^{2} \mathrm{H}_{6}$-DMS from ${ }^{2} \mathrm{H}_{6}$ $\mathrm{DMSP}_{\mathrm{d}}$, while DMS production from DMSO reduction was measured as the rate of accumulation of ${ }^{13} \mathrm{C}_{2}$-DMS derived from ${ }^{13} \mathrm{C}_{2}-\mathrm{DMSO}_{\mathrm{d}}$ (Figure S2). Gross DMS consumption was measured as the rate of depletion of deuterated ${ }^{2} \mathrm{H}_{3}$-DMS (Figure S2). Rates of tracer production and consumption were scaled to the concentrations of total DMS, DMSP ${ }_{d}$ and $\mathrm{DMSO}_{\mathrm{d}}$ in samples to approximate the in situ turnover rates of these compounds (see auxiliary material for details). We constructed a simple mass balance equation, which assumes that the observed change in the DMS pool equals the amount produced by DMSP cleavage and DMSO reduction minus the loss due to gross DMS consumption (losses due to gas exchange did not occur in our incubation experiments). Thereafter, any imbalances resulting in unexplained net DMS production point to other unspecified (and difficult to trace) processes, most likely tied to DMS release from the particulate pool. These processes include direct DMS excretion from particles, as well as the conversion of unlabelled DMSP or DMSO that has leaked from cells into the dissolved pool. Rearranging the mass balance to solve for the unknown net source yields equation (1).

$$
\begin{aligned}
\mathrm{d}\left[\mathrm{DMS}_{\text {ex }}\right] / \mathrm{dt}= & \mathrm{d}\left[{ }^{1} \mathrm{H}_{6}{ }^{12} \mathrm{C}_{2}-\mathrm{DMS}\right] / \mathrm{dt}+\mathrm{d}\left[{ }^{2} \mathrm{H}_{3}-\mathrm{DMS}\right] / \mathrm{dt} \\
& -\mathrm{d}\left[{ }^{2} \mathrm{H}_{6}-\mathrm{DMS}\right] / \mathrm{dt}-\mathrm{d}\left[{ }^{13} \mathrm{C}_{2}-\mathrm{DMS}\right] / \mathrm{dt}
\end{aligned}
$$

The left hand term in the equation represents an unspecified source attributed to particulate DMS release. The right hand terms in the equation represent the net change in DMS concentrations, gross DMS consumption, the production of DMS from DMSP cleavage, and the production of DMS from DMSO reduction.

\section{Results}

[6] Our measurements revealed considerable variability in the concentrations of DMS, DMSP and DMSO both across sampling sites (Figure 1), and with depth at individual sampling locations (Figure S3). Mean DMS, $\mathrm{DMSP}_{\mathrm{t}}$, and $\mathrm{DMSO}_{\mathrm{t}}$ concentrations in sea ice brines were $33.2 \pm 4.78 \mathrm{nM}$ (std. err.), $305 \pm 54.8 \mathrm{nM}$ and $138 \pm 14.5 \mathrm{nM}$, with maximum values of $277 \mathrm{nM}, 2990 \mathrm{nM}$, and $471 \mathrm{nM}$, respectively. The concentrations of $\mathrm{DMS} / \mathrm{P} / \mathrm{O}$ were all significantly (at least five-fold) higher in sea-ice brines than in the icecovered seawater (Figure 1; $t \geq 9.5$ and $p<0.0001$ across four unequal variance $\mathrm{t}$-tests). Given our sampling technique, our values may underestimate the particulate $\mathrm{DMS} / \mathrm{P} / \mathrm{O}$ fraction present in ice brines due to the adhesion of particulates on brine channel walls [Thomas and Papadimitriou, 2003; Tison et al., 2010], leading to even greater differences between brine and seawater DMS concentrations, the latter of which were uniformly low.

[7] We observed significant phytoplankton biomass in seaice and brines typically exceeding $10 \mu \mathrm{g} \mathrm{L}^{-1} \mathrm{Chl} a$ (and in several cases exceeding $100 \mu \mathrm{g} \mathrm{L}^{-1}$ ) in conjunction with high concentrations of methylated S compounds (Figure S3). The concentrations of $\mathrm{DMS} / \mathrm{P} / \mathrm{O}$ were generally highest in brines collected near the upper ice surface, decreasing with ice core depth $\left(r^{2}=0.14, \mathrm{p}<0.005\right.$; Figure 1, Figure S3). This depth-dependent distribution was particularly evident for $\mathrm{DMSO}_{\mathrm{t}}$ and $\mathrm{DMSP}_{\mathrm{t}}$, which is consistent with increased photo-oxidation of DMS to DMSO in high light regimes and the hypothesized role of reduced S compounds in UV protection of ice algae [Hatton et al., 2004; Stefels et al., 2007]. In a multiple regression, $\mathrm{DMSP}_{\mathrm{t}}$ and $\mathrm{DMSO}_{\mathrm{t}}$ concentrations explained the majority of variance in DMS across our samples $\left(r^{2}=0.66, p<0.001\right.$; data not shown $)$. DMSP ${ }_{t}$ concentrations were also best predicted by a combination of Chla concentration and core depth $\left(r^{2}=0.51, p<0.001\right.$; data not shown).

[8] Using our isotope tracer approach, we observed significant $(\mathrm{p}<0.05)$ rates of gross DMS production from multiple sources in sea-ice brines, concurrent with net production of unlabeled DMS. Figure 2 shows time-course data for one experiment (station 27) in which we measured a net DMS production rate of $17 \pm 3.5 \mathrm{nM} \mathrm{d}^{-1}$ in a sea ice brine sample (Figure 2a). Gross DMS consumption, which includes the biotic consumption of DMS as well as the photooxidation of DMS to DMSO (measured as the disappearance of ${ }^{2} \mathrm{H}_{3}$-DMS), reached $88 \pm 20 \mathrm{nM} \mathrm{d}^{-1}$ (Figure 2b). Summing net DMS production and gross DMS consumption yielded a gross DMS production rate of $105 \pm 24 \mathrm{nM} \mathrm{d}^{-1}$ 
(i.e. $17+88$ ). Our direct measurements show that $25 \pm$ $6.9 \mathrm{nM} \mathrm{d}^{-1}$ DMS was produced from DMSP cleavage at this station (Figure 2c), while $96 \pm 26 \mathrm{nM} \mathrm{d}^{-1}$ was produced from DMSO reduction (Figure 2d). In this experiment, the measured rates yield a mass balance of production and consumption terms within the error of our measurements. As discussed below, results from other sampling stations did not yield an exact mass balance, suggesting that direct DMS release from the particulate biological pool (which we did not measure directly) contributed significantly to gross DMS production.

[9] Similar results to Figure 2 were observed in sea-ice brines sampled across our study region, i.e. rapid DMS consumption and production through various pathways (Figure 3). In many cases, DMSO reduction rates (range 75$210 \mathrm{nM} \mathrm{d}^{-1}$; mean $150 \pm 22 \mathrm{nM} \mathrm{d}^{-1}$ ) dominated DMS production in brine samples (Figure 3 ), with rates $>3$-fold higher than DMSP cleavage (range $21-62 \mathrm{nM} \mathrm{d}^{-1}$; mean $\left.37 \pm 6 \mathrm{nM} \mathrm{d}^{-1}\right)$. DMSO yields varied from $20 \%-100 \%$ with a mean of $45 \%$, although these values are subject to significant uncertainty (see auxiliary material for details). Although DMSO reduction was the dominant measured source of DMS in most of our tracer experiments, we estimated a high

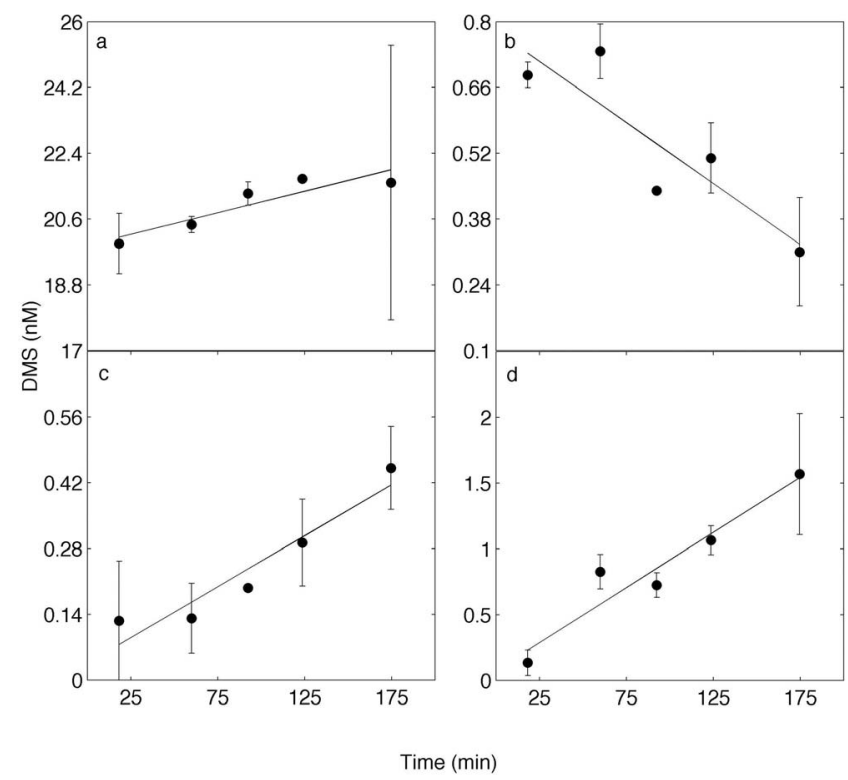

Figure 2. Time course data showing the change in concentrations of different isotopically-labeled DMS species used to calculate consumption and production rates at station 27. The net change of unlabeled DMS (mass 62) is shown in panel (a). Gross consumption is calculated from the ${ }^{2} \mathrm{H}_{3}$-DMS (mass 65) tracer depletion rate (Figure 2b). DMSP cleavage is calculated from the accumulation of ${ }^{2} \mathrm{H}_{6}$-DMS (mass 68) (Figure 2c), and DMSO reduction is calculated from the accumulation of ${ }^{13} \mathrm{C}_{2}$-DMS (mass 64) (Figure 2d). Error bars represent the standard error of triplicates. These tracer turnover rates were subsequently scaled using natural $\mathrm{DMS} / \mathrm{P} / \mathrm{O}$ concentrations to calculate in situ production and consumption rates. At this station $25 \pm 6.9 \mathrm{nM} \mathrm{d}^{-1}$ DMS was produced from DMSP cleavage, $96 \pm 26 \mathrm{nM} \mathrm{d}^{-1}$ DMS was produced from the DMSO reduction, and DMS was consumed at the rate of $88 \pm 20 \mathrm{nM} \mathrm{d}^{-1}$. The net DMS production rate was $17 \pm 3.5 \mathrm{nM} \mathrm{d}^{-1}$.

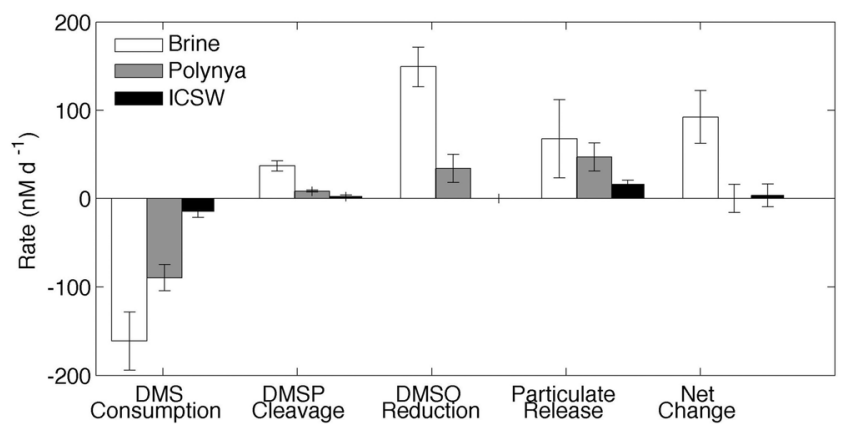

Figure 3. Summary of DMS production and consumption rates measured in isotope tracer experiments in sea ice brines (station 27, 30, 31, 43), ice-covered seawater (ICSW) (at stations 31 and 43) and ice-free seawater from the Ross Sea polynya (Station 44). DMS release from the particulate biological pool is calculated from the mass balance of measured production and consumption rates as in equation (1). Bars show the mean of all rate measurements and error bars represent standard errors of the means.

$\left(>50 \mathrm{nM} \mathrm{d}^{-1}\right.$ ) apparent particulate release of DMS at several ice stations based on the mass balance approach presented in equation (1). These high DMS release rates, which may reflect algal lysis, account for the large variability seen in the inferred biological DMS release in Figure 3. Rates of gross DMS consumption and production were significantly higher in sea ice brines (range 57-250; mean $160 \pm 33$ ) than in underlying ice-covered seawater. Intense DMS cycling resulted in higher net DMS production in the sea ice brines (93 $\pm 48 \mathrm{nM} \mathrm{d}^{-1}$; Figure 3) relative to the ice-covered seawater samples $\left(3.5 \pm 13 \mathrm{nM} \mathrm{d}^{-1}\right)$.

[10] Although the highest rates of DMSO reduction were observed in sea ice slush and brines, we also observed significant DMSO reduction rates $\left(34 \pm 16 \mathrm{nM} \mathrm{d}^{-1}\right)$ in ice-free waters of the Ross Sea polynya (Station 41) sampled in mid January. These rates of DMSO reduction were considerably higher than the rates of DMSP cleavage $\left(8.4 \pm 1.1 \mathrm{nM} \mathrm{d}^{-1}\right)$. We estimated a $\sim 30 \%$ DMSO yield at this site due to high DMSO turnover $(\sim 100 \mathrm{nM} /$ day $)$, providing further evidence for the widespread importance of DMSO as a source of DMS. In contrast to the ice brine samples, however, we observed very small net changes in DMS concentrations in our Ross Sea samples. Correlations between rate constants $\left(\mathrm{d}^{-1}\right)$ of key DMS production pathways in the Ross Sea polynya and sea ice brines indicate rapid DMS/O cycling and ties between particulate release of DMS and DMSP cleavage in both environments. In brines and in the Ross Sea polynya, rate constants of DMSO reduction and DMS consumption were closely correlated $\left(r^{2}=0.92, p<0.01\right)$, as were DMSP cleavage and the apparent release of DMS from the particulate pool $\left(r^{2}=0.77, p<0.05\right)$.

\section{Discussion}

[11] Our results indicate that active microbial cycling in Antarctic sea ice leads to the accumulation of high DMS concentrations due to rapid DMSO reduction, DMSP cleavage, and in some cases the likely release of DMS from the particulate biological pool. We present novel DMS turnover rate measurements in sea-ice samples, and the first direct 
quantification of oceanic DMSO reduction to DMS (as opposed to net changes in DMSO concentrations). While DMSP has typically been considered the main oceanic source of DMS, our data suggest that rapid biological DMSO reduction dominates DMS production in varied Antarctic sea-ice environments. The abiotic disproportionation of DMSO, which forms DMS and dimethyl sulfone, has been observed in aerobic freshwater systems. However, the maximum rates of this reaction $\left(<1 \mathrm{nM} \mathrm{d}^{-1}\right)$ are considerably lower than the DMSO reduction rates reported here, and negligible in comparison to the biological reduction of DMSO to DMS observed in freshwater systems, where DMSO competes with oxygen as an electron acceptor and DMSO reduction rates are well correlated with bulk bacterial respiration [Griebler, 1997; Griebler and Slezak, 2001; Harvey and Lang, 1986]. Bacterial DMSO-reducing enzymes are widespread and appear to be bound to the cellular membrane [Gralnick et al., 2006; McCrindle et al., 2005; Vila-Costa et al., 2006; Zinder and Brock, 1978], facilitating rapid biological DMSO reduction [Griebler, 1997; Griebler and Slezak, 2001]. Recent work with laboratory cultures suggests that phytoplankton may also be an important source of biological DMSO reduction to DMS in aerobic marine environments [Spiese et al., 2009]. Our data indicate an important role of DMSO reduction as a major source of DMS in marine systems and rapid DMS/DMSO cycling where DMSO concentrations are high. At present, we are unable to evaluate the relative contributions of sea ice bacteria and algae to DMSO reduction.

[12] DMSO concentrations are particularly high in the Antarctic SIZ, likely due to high rates of biotic production, photo-oxidation, and possible deposition in snow [del Valle et al., 2007; del Valle et al., 2009; Sciare et al., 1998]. Although in situ biological production of particulate DMSO has thus far not been examined in the Southern Ocean, this process has been observed in a variety of phytoplankton and bacterial species as well as in natural plankton communities [Hatton and Wilson, 2007; Simo et al., 1998; Simo and Vila-Costa, 2006; Vila-Costa et al., 2008]. It has been hypothesized that both DMS and DMSO function as cellular anti-oxidants and that DMS oxidation to DMSO may play a role in cellular photo-protection [Sunda et al., 2002; Hatton et al., 2004]. We thus suggest that rapid redox cycling between DMS and DMSO plays an important role in photoprotective mechanisms of Antarctic microbes, and accounts for the exceptionally high concentrations of these compounds in the Southern Ocean SIZ. Future work may determine if rapid DMS/P/O cycling occurs in slushes and melt ponds as well as sea ice brines, as suggested by similarly high $\mathrm{DMS} / \mathrm{P} / \mathrm{O}$ concentrations we observed in these samples. Additionally, our work and that of others [del Valle et al., 2009; Hatton et al., 2004; Kiene et al., 2007] has documented high DMS/O concentrations and turnover rates in ice-free Antarctic polynya waters, particularly under late summer conditions of high solar irradiance and mixed layer stratification, suggesting that our observations may be relevant beyond the SIZ.

\section{Conclusions}

[13] Recent modeling studies reporting large climatedependent changes in Southern Ocean DMS emissions have not explicitly included the potential influence of the vast SIZ.
Our results and those of several recent studies indicate, however, that the SIZ may contribute significantly to DMS cycling in the Southern Ocean. While it has typically been assumed that gas exchange is severely limited in sea ice, significant DMS fluxes have recently been measured over snow and ice covered waters [Zemmelink et al., 2008]. The SIZ, by virtue of its active microbial populations, high DMS concentrations, and vast areal extent could play a significant role in climate-dependent DMS feedback mechanisms. Furthermore, melt-induced surface water stratification could lead to greater DMS/DMSO cycling in high irradiance surface waters as we observed in the Ross Sea polynya. In order to predict the climate-sensitivity of the Southern Ocean DMS cycle, it is thus critical to understand the factors controlling DMS cycling in the Antarctic water column and the SIZ, and their sensitivity to various environmental perturbations.

[14] Acknowledgments. We would like to thank Zachary Brown for field assistance with ice core sampling and processing of chlorophyll measurements. We would also like to thank the Raytheon Polar Services Science support staff and the crew and scientific team of the Oden for logistical and field support. This work was supported in part by Woods Hole Oceanographic Institution's Ocean Life Institute and by NSF grant ANT-0838872 to KRA.

\section{References}

Bates, T. S., et al. (1992), Sulfur emissions to the atmosphere from natural sources, J. Atmos. Chem., 14(1-4), 315-337, doi:10.1007/BF00115242.

Bopp, L., et al. (2003), Potential impact of climate change on marine dimethyl sulfide emissions, Tellus, Ser. B, 55(1), 11-22, doi:10.1034/ j.1600-0889.2003.042.x.

Bopp, L., et al. (2004), Will marine dimethylsulfide emissions amplify or alleviate global warming? A model study, Can. J. Fish. Aquat. Sci., 61(5), 826-835, doi:10.1139/f04-045.

Brabant, F., et al. (2011), A robust approach for the determination of dimethylsulfone in sea ice, Limnol. Oceanogr. Methods, 9, 261-274, doi:10.4319/lom.2011.9.261.

Breider, T. J., et al. (2010), Impact of BrO on dimethylsulfide in the remote marine boundary layer, Geophys. Res. Lett., 37, L02807, doi:10.1029/2009GL040868.

Cameron-Smith, P., et al. (2011), Changes in dimethyl sulfide oceanic distribution due to climate change, Geophys. Res. Lett., 38, L07704, doi:10.1029/2011GL047069.

Charlson, R. J., et al. (1987), Oceanic phytoplankton, atmospheric sulfur, cloud albedo and climate, Nature, 326(6114), 655-661, doi:10.1038/ $326655 \mathrm{a} 0$.

Chin, M., et al. (2000), Atmospheric sulfur cycle simulated in the global model GOCART: Model description and global properties, J. Geophys. Res., 105(D20), 24,671-24,687, doi:10.1029/2000JD900384.

del Valle, D. A., et al. (2007), Light-stimulated production of dissolved DMSO by a particle-associated process in the Ross Sea, Antarctica, Limnol. Oceanogr., 52(6), 2456-2466, doi:10.4319/lo.2007.52.6.2456.

del Valle, D. A., et al. (2009), Dissolved DMSO production via biological and photochemical oxidation of dissolved DMS in the Ross Sea, Antarctica, Deep Sea Res., Part I, 56(2), 166-177, doi:10.1016/j.dsr.2008.09.005.

Fuse, H., et al. (1995), Transformation of dimethyl sulfide and relatedcompounds by cultures and cell-extracts of marine phytoplankton, Biosci. Biotechnol. Biochem., 59(9), 1773-1775, doi:10.1271/bbb.59.1773.

Gabric, A. J., et al. (2001), Dimethylsulphide production in the subantarctic southern ocean under enhanced greenhouse conditions, Tellus, Ser. B, 53(3), 273-287, doi:10.1034/j.1600-0889.2001.01244.x.

Gabric, A. J., et al. (2004), Modeling estimates of the global emission of dimethylsulfide under enhanced greenhouse conditions (vol 18, art no GB2014, 2004), Global Biogeochem. Cycles, 18, GB3016, doi:10.1029/ 2004GB002337.

Gonzalez, J. M., et al. (1999), Transformation of sulfur compounds by an abundant lineage of marine bacteria in the alpha-subclass of the class Proteobacteria, Appl. Environ. Microbiol., 65(9), 3810-3819.

Gralnick, J. A., et al. (2006), Extracellular respiration of dimethyl sulfoxide by Shewanella oneidensis strain MR-1, Proc. Natl. Acad. Sci. U. S. A., 103(12), 4669-4674, doi:10.1073/pnas.0505959103.

Griebler, C. (1997), Dimethylsulfoxide (DMSO) reduction: A new approach to determine microbial activity in freshwater sediments, J. Microbiol. Methods, 29(1), 31-40, doi:10.1016/S0167-7012(97) 00990-1. 
Griebler, C., and D. Slezak (2001), Microbial DMSO reduction is widespread among microorganisms and is therefore proposed as a reliable activity parameter, in Proc. Int. Assoc. Theor. Appl. Limnol., 27(4), 2492-2497, doi:10.1128/AEM.67.1.100-109.2001.

Harvey, G. R., and R. F. Lang (1986), Dimethylsulfoxide and dimethylsulfone in the marine atmosphere, Geophys. Res. Lett., 13(1), 49-51, doi:10.1029/GL013i001p00049.

Hatton, A. D., and S. T. Wilson (2007), Particulate dimethylsulphoxide and dimethylsulphoniopropionate in phytoplankton cultures and Scottish coastal waters, Aquat. Sci., 69(3), 330-340, doi:10.1007/s00027-0070891-4.

Hatton, A. D., et al. (2004), The role of dimethylsulphoxide in the marine biogeochemical cycle of dimethylsulphide, in Oceanogr. Mar. Biol. Annu. Rev., 42, 29-55.

Kiene, R. P., et al. (2000), New and important roles for DMSP in marine microbial communities, J. Sea Res., 43(3-4), 209-224, doi:10.1016/ S1385-1101(00)00023-X.

Kiene, R. P., et al. (2007), Distribution and cycling of dimethylsulfide, dimethylsulfoniopropionate, and dimethylsulfoxide during spring and early summer in the Southern Ocean south of New Zealand, Aquat. Sci., 69(3), 305-319, doi:10.1007/s00027-007-0892-3.

Korhonen, H., et al. (2008), Influence of oceanic dimethyl sulfide emissions on cloud condensation nuclei concentrations and seasonality over the remote Southern Hemisphere oceans: A global model study, J. Geophys. Res., 113(D15), D15204, doi:10.1029/2007JD009718.

Lana, A., et al. (2011), An updated climatology of surface dimethlysulfide concentrations and emission fluxes in the global ocean, Global Biogeochem. Cycles, 25, GB1004, doi:10.1029/2010GB003850.

McCrindle, S. L., U. Kappler, and A. G. McEwan (2005), Microbial dimethylsulfoxide and trimethylamine-N-oxide respiration, in Adv. Microb. Physiol., 50, 147-198, doi:10.1016/S0065-2911(05)50004-3.

Sciare, J., et al. (1998), Seasonal variation of dimethylsulfoxide in rainwater at Amsterdam island in the southern Indian Ocean: Implications on the biogenic sulfur cycle, J. Atmos. Chem., 30(2), 229-240, doi:10.1023/ A:1005983625947.

Shaw, G. E. (1983), Bio-controlled thermostasis involving the sulfur cycle, Clim. Change, 5(3), 297-303, doi:10.1007/BF02423524.

Simo, R., and C. Pedros-Alio (1999), Role of vertical mixing in controlling the oceanic production of dimethyl sulphide, Nature, 402(6760), 396-399, doi:10.1038/46516.

Simo, R., and M. Vila-Costa (2006), Ubiquity of algal dimethylsulfoxide in the surface ocean: Geographic and temporal distribution patterns, Mar. Chem., 100(1-2), 136-146, doi:10.1016/j.marchem.2005.11.006.

Simo, R., et al. (1998), Particulate dimethyl sulphoxide in seawater: production by microplankton, Mar. Ecol. Prog. Ser., 167, 291-296, doi:10.3354/meps167291.

Spiese, C. E., et al. (2009), Reduction of dimethylsulfoxide to dimethylsulfide by marine phytoplankton, Limnol. Oceanogr., 54(2), 560-570, doi:10.4319/1o.2009.54.2.0560.
Stefels, J., et al. (2007), Environmental constraints on the production and removal of the climatically active gas dimethylsulphide (DMS) and implications for ecosystem modeling, Biogeochem., 83(1-3), 245-275, doi:10.1007/s10533-007-9091-5.

Sunda, W., et al. (2002), An antioxidant function for DMSP and DMS in marine algae, Nature, 418, 245-275.

Thomas, D. N., and S. Papadimitriou (2003), Biogeochemistry of sea ice, in Sea Ice: An Introduction to Its Physics, Biology, Chemistry and Geology, edited by D. N. Thomas and G. S. Dieckmann, pp. 267-302, Blackwell Science, Oxford, UK.

Tison, J. L., et al. (2010), High-resolution dimethyl sulfide and dimethylsulfoniopropionate time series profiles in decaying summer first-year sea ice at Ice Station Polarstern, western Weddell Sea, Antarctica, J. Geophys. Res., 115, G04044, doi:10.1029/2010JG001427.

Trevena, A. J., and G. B. Jones (2006), Dimethylsulphide and dimethylsulphoniopropionate in Antarctic sea ice and their release during sea ice melting, Mar. Chem., 98(2-4), 210-222, doi:10.1016/j.marchem.2005. 09.005 .

Vallina, S. M., and R. Simo (2007), Strong relationship between DMS and the solar radiation dose over the global surface ocean, Science, 315(5811), 506-508, doi:10.1126/science.1133680.

Vila-Costa, M., et al. (2006), Phylogenetic identification and metabolism of marine dimethylsulfide-consuming bacteria, Environ. Microbiol., 8(12), 2189-2200, doi:10.1111/j.1462-2920.2006.01102.x.

Vila-Costa, M., et al. (2008), Seasonal variability of the dynamics of dimethylated sulfur compounds in a coastal northwest Mediterranean site, Limnol. Oceanogr., 53(1), 198-211, doi:10.4319/lo.2008.53.1.0198.

Zemmelink, H. J., et al. (2005), Emission of dimethylsulfide from Weddell Sea leads, Geophys. Res. Lett., 32, L23610, doi:10.1029/2005GL024242.

Zemmelink, H. J., et al. (2008), Dimethylsulfide emissions over the multiyear ice of the western Weddell Sea, Geophys. Res. Lett., 35, L06603, doi:10.1029/2007GL031847.

Zinder, S. H., and T. D. Brock (1978), Production of methane and carbon dioxide from methane thiol and dimethyl sulfide by anaerobic lakesediments, Nature, 273(5659), 226-228, doi:10.1038/273226a0.

K. R. Arrigo, Department of Environmental Earth Systems Science, Stanford University, 473 Via Ortega, Stanford, CA 94305, USA. (arrigo@stanford.edu)

E. C. Asher and P. D. Tortell, Department of Earth and Ocean Sciences, University of British Columbia, 2146 Health Sciences Mall, Vancouver, BC V6T 1Z3, Canada. (easher@eos.ubc.ca; ptortell@eos.ubc.ca)

J. W. H. Dacey, Biology Department, Woods Hole Oceanographic Institution, 226 Woods Hole Rd., Woods Hole, MA 02543, USA. (jdacey@whoi.edu)

M. M. Mills, Department of Environmental Earth Systems Science, Stanford University, 397 Panama Mall, Stanford, CA 94305-2215, USA. (mmills@stanford.edu) 